\title{
Dying with dignity
}

\author{
Rory CM McGouran
}

\section{Dying with dignity}

Miss Smith, aged 80, was admitted to the cottage hospital after a stroke. She was looked after by the senior partner in a local practice. His examination confirmed a hemiparesis, hemianopia and aphasia. She was in slow atrial fibrillation and her blood pressure was 220/120 $\mathrm{mmHg}$. Nothing he found suggested that blood tests would be helpful in her management, so he asked for none. He could see no indication for medication. The cottage hospital had no X-ray facilities.

She was nursed on a small female ward, bright and cheerful. There was only one trained nurse on each shift but the auxillaries were kind and the atmosphere was relaxed. She choked on her drinks initially but soon was able to swallow again. The general practitioner explained to her niece, a lawyer, that the stroke was serious; she might recover, but equally she might die. She had been active and independent until now and they agreed that if her time had come she would want to go quickly.

She rallied for a time but then became chesty. No antibiotics were prescribed and she died peacefully next day.

\section{'Best practice'}

Miss Smith, aged 80, was admitted to the district general hospital after a stroke. The casualty officer's examination confirmed a hemiparesis, hemianopia and aphasia. She was in slow atrial fibrillation and her blood pressure was 220/120 mmHg. The medical admissions unit (MAU) was full, so she waited on a trolley in accident and emergency for six hours. The corridor was on her hemianopic side so she could see only the wall.

Because of the pressure on the MAU the sixbedded units contained male and female patients. Miss Smith had never had a man in her bedroom before, but now she had two. On her good side a heavily tattooed drunk snored loudly, while across the room a confused old man tugged at his urinary catheter, his bedclothes on the floor.

The houseman came to see her, and was just in time to stop the auxiliary offering her a cup of tea before she had a formal swallowing assessment by a speech therapist. He examined her and returned to the nursing station to request investigations. These were routine in all cases of stroke: a full blood count, C-reactive protein, urea and electrolytes, liver function tests, thyroid function and cholesterol. A chest $\mathrm{X}$-ray was ordered and an urgent computed axial tomography (CAT) scan. Nitrites were found in her urine, so a urinary tract infection was assumed and broad spectrum antibiotics started.

The houseman returned to Miss Smith to discuss with her the trust resuscitation policy. He asked whether she would want to be resuscitated if she died. She was uncertain what he meant - and anyhow was unable to answer. Referring to the guidelines, he explained that her heart might stop because of problems unrelated to her stroke and could possibly be restarted by the crash team. The trust resuscitation policy required that she be given the opportunity to decide on her management. When she did not respond, he realised she had gone to sleep. He felt that she was not in a position to make this decision for herself.

Later, the specialist registrar met her niece. He had been informed that she was a lawyer. He explained that her aunt had suffered a serious stroke; she might recover or she might die. However, there was good evidence that further cardiovascular events could be prevented by appropriate medication. If her blood pressure remained high they would treat that, and if her cholesterol was high they would treat that too. Both these treatments had been shown to be of value in younger patients and it would be ageist to deny them to her aunt. The atrial fibrillation was also a concern as this was a significant risk factor in stroke. Ideally, she should be anticoagulated, but the timing of this would depend on the CAT scan which would reveal if the stroke was haemorrhagic. Because so much could be done, the registrar felt that Miss Smith should be given every chance now - after all, she had previously been active and independent. Her niece therefore agreed on her behalf that she should be resuscitated.

The consultant saw Miss Smith on the evening MAU ward round, his 20th admission that day and the third old lady with a stroke. A quick examination confirmed the diagnosis and he moved on to the next bed to discharge the tattooed drunk.

Miss Smith remained on the MAU for a further day as there was no bed on the medical wards. On the ward round next morning the consultant of the day noted that she had already been assessed by his

\section{Rory CM}

McGouran MD

FRCP, Consultant

Physician, Queen

Elizabeth Hospital,

Kings Lynn

Clin Med JRCPL

2002; $2: 43-44$ 
colleague and moved quickly on. She was very thirsty, but the speech therapist had not come to make the swallowing assessment so she was not offered a drink. The ward was understaffed and busy with new admissions and a drip was not considered.

That evening, she was moved to an acute ward. A CAT scan next day showed a parietal infarct, so she was started on subcutaneous heparin pending oral anticoagulation when her swallowing had been assessed. The houseman set up a drip at the ward sister's request but it tissued unnoticed a few hours later.

She was desperately thirsty next morning. She could see a jug of water beside the bed and struggled to reach it, but the hemiparesis, dehydration and antihypertensive medication were too much for her and she fell and banged her head on the edge of the locker. A three-page accident form was filled in, and an adverse incident report completed and sent to the risk management office. She became increasingly drowsy over the next 24 hours and a second CAT scan confirmed a subdural haematoma. The risk managers were concerned that the trust might be held liable for inadequate supervision leading to the fall. They were also worried about accusations of ageism if she were denied surgical evacuation of the haematoma. While the houseman was contacting the neurosurgical centre she had a cardiac arrest.

Attempts were then made to resuscitate her. Several calcified costal cartilages gave way under vigorous cardiac massage and a faltering cardiac output was achieved. She regained consciousness sufficiently to be aware of the terrible pain in her chest and whimpered quietly. An elective admission for abdominal aneurysm repair was cancelled so that she could be transferred to the intensive therapy unit for ventilation.

Her niece arrived and was devastated by her aunt's condition. The registrar had been advised to remind her tactfully that she had agreed to resuscitation and she was consumed with guilt.

Miss Smith was transferred by ambulance on a ventilator later that day. Her heart stopped on the journey and, despite the flail chest, could not be restarted. She was confirmed dead on arrival at the neurosurgical centre.

Address for correspondence: Dr R McGouran, Queen Elizabeth Hospital, Gayton Road,

Kings Lynn, Norfolk PE30 4ET

E-mail: rorymcgouran@hotmail.com 